\title{
The influence of intense stress on the formation of aggressive reactions and ideas of revenge in the population of the post-war region
}

\author{
Islam $\mathrm{Khazhuev}^{1 *}$, and Aslanbek Saidov ${ }^{2}$ \\ ${ }^{1}$ CHSPU, SPPD department, 364031, Grozny, Russia \\ ${ }^{2}$ CHSPU, psychology department, 364031, Grozny, Russia
}

\begin{abstract}
The article presents the results of a study of the specifics of the formation of aggressive reactions and ideas of revenge in the context of experiencing high-intensity stress among people who have experienced traumatic stress in a long-term emergency. The empirical study involved 100 respondents, characterized by the presence of various traumatic experiences, mainly of military etiology. The empirical results of the study indicate the presence of statistically significant relationships between the signs of post-traumatic stress and various forms of aggressive behavior. The empirical results of the study indicate the presence of statistically significant relationships between the signs of post-traumatic stress and various forms of aggressive behavior. Thus, the experience of posttraumatic stress at a remote stage of an extreme situation is accompanied by an increase in suspicion, resentment, anger and irritation reactions, as well as a decrease in the ability of the individual to compromise. In addition, it is also found that persons who have a predominant rate of aggressive reactions, manifested in the form of suspicion and a tendency to attack the style of behavior and communication, characterized by a high level of fixation on the ideas of revenge.
\end{abstract}

\section{Introduction}

Modern man is constantly exposed to various stressful influences, on the frequency and intensity of which depends not only the state of his mental health, but also effective functioning in the social, interpersonal and professional aspects of life. Experience of intense stress reactions can cause a constant expenditure of psycho-emotional energy, inefficient use of cognitive and socio-psychological resources of the individual [1-3]. In this regard, as shown by numerous studies, the most destructive for the human psyche are stress experiences caused by psych traumatic events (for example, wars, acts of terror, real or imaginary threat to life and health, technogenic and natural disasters, etc.), which can cause mental disorders in almost any person, regardless of national and religious affiliation, demographic and social characteristics [4-9].

\footnotetext{
*Corresponding author: hazhuev@mail.ru
} 
The result of experiencing a psychotraumatic event is the development of not only intense stress reactions, but also transformations in the structure of the personality, emotional and cognitive disorders, disorders of social adaptation against the background of aggressive impulses and a tendency to violent behavior. Aggressiveness and aggressive reactions in this regard are natural emotional and personal manifestations of a person experiencing intense stress. It can even be said that aggressive impulses and reactions in the process of personality transformation under the influence of a psycho-traumatic event can acquire the property of universal patterns of reaction and behavior due to the fixation of the human psyche on the images of violence and trauma [4-6, 8, 10-18].

Based on the above, we conducted an empirical study of the specifics of the influence of intense stress experiences manifested through post-traumatic stress in the population of the post-war region on the formation of aggressive reactions and impulses.

An empirical study was conducted among the population of the Chechen Republic (CHR), where the so-called "counter-terrorism operation" regime was maintained for a long time. The study involved 100 people (44 men and 56 women aged 25 to 55 years) living in various regions of the republic.

The following methods were used as diagnostic methods Impact of Event Scale-R (adaptation by N. V. Tarabrina, 2001); Spielberger's State Trait Anger Expression Inventory STAXI; P.A. Kovalev's personal aggressiveness questionnaire.

So, in the beginning, to achieve the purpose of the study (the study of the influence of the intensity of stressful experiences on the formation of aggressive reactions and ideas of revenge) were analyzed the relationship intensity of stressful experiences (the phenomena of post-traumatic stress disorder) and various aggressive reactions (using the Spearman's rank-order correlation).

Thus, as a result of the correlation analysis of statistical data of respondents ' research, obtained using Spielberger's State Trait Anger Expression Inventory STAXI and Impact of Event Scale-R (aimed at diagnosing the level of post-traumatic stress), reliable interrelations of positive orientation between individual variables of the study were revealed. It was found that such scales of the STAXI questionnaire as the state of momentary anger $(\mathrm{R}=0,344 ; \mathrm{P}=0,000)$, the tendency to anger and irritability $(\mathrm{R}=0,254$; $\mathrm{P}=0,011)$, as well as the orientation of anger inward $(\mathrm{R}=0,268 ; \mathrm{P}=0.007)$ are positively associated with signs of posttraumatic stress (PTSD). At the same time, the variable angertemperament $(\mathrm{R}=0,217 ; \mathrm{P}=0,030)$ and the variable anger-reaction $(\mathrm{R}=0,200 ; \mathrm{P}=0,046)$ are positively associated with the General PTS index (by Impact of Event Scale-R).

However, the analysis also revealed correlations between intense stress experiences, manifested in the form of post-traumatic stress and individual aggressive tendencies (with P. A. Kovalev's personal aggressiveness questionnaire). Thus, it was found that the growth of indicators of the level of post-traumatic stress (diagnosed using the Impact of Event Scale-R) may be accompanied by an increase in the propensity of the individual to resentment $(\mathrm{R}=0,448 ; \mathrm{P}=0,000)$ and suspicion $(\mathrm{R}=0,225 ; \mathrm{P}=0.024)$, against the background of reduced propensity to compromise $(\mathrm{R}=-0.190 ; \mathrm{P}=0.059)$.

In addition, as part of the analysis of empirical research data, we also investigated the parameters of aggressive impulses of respondents depending on the level of severity of the overall PTSD index (see table 1).

Table 1. The severity of aggressive reactions depending on the level of PTS

\begin{tabular}{|l|l|c|l|}
\hline $\begin{array}{l}\text { The scale of } \\
\text { aggressiveness }\end{array}$ & $\begin{array}{l}\text { Severity level of } \\
\text { PTS }\end{array}$ & Assigned rank & $\mathrm{X}^{2} / \mathrm{P}$ \\
\hline \multirow{2}{*}{$\begin{array}{l}\text { Momentary state of } \\
\text { anger } *\end{array}$} & Low & 1 & \multirow{2}{*}{$\chi^{2}=11,721$} \\
\cline { 2 - 3 } & Average level & 2 & \\
\cline { 2 - 3 } & High level & 3 & $\mathrm{P}=0,003$ \\
\hline
\end{tabular}




\begin{tabular}{|c|c|c|c|}
\hline \multirow{3}{*}{$\begin{array}{l}\text { Tendencies to } \\
\text { irritability and anger* }\end{array}$} & Low level & 1 & \multirow{3}{*}{$\begin{array}{l}\chi^{2}=6,612 \\
P=0,037\end{array}$} \\
\hline & Average level & 3 & \\
\hline & High level & 2 & \\
\hline \multirow{3}{*}{$\begin{array}{l}\text { Expression of anger } \\
\text { inward * }\end{array}$} & Low level & 1 & \multirow[t]{3}{*}{$\chi^{2}=7,124$} \\
\hline & Average level & 2 & \\
\hline & High level & 3 & \\
\hline \multirow[t]{3}{*}{ Touchiness** } & Low level & 1 & \multirow[t]{3}{*}{$\chi^{2}=18,641$} \\
\hline & Average level & 2 & \\
\hline & High level & 3 & \\
\hline \multirow{3}{*}{$\begin{array}{l}\text { A willingness to } \\
\text { compromise }{ }^{* *}\end{array}$} & Low & 3 & \multirow[t]{3}{*}{$\chi^{2}=5,855$} \\
\hline & Average level & 2 & \\
\hline & High level & 1 & \\
\hline
\end{tabular}

Note: the table shows only those variables of questionnaires that have statistical significance.

* Spielberger's State Trait Anger Expression Inventory STAXI, ** P.A. Kovalev's personal aggressiveness questionnaire.

As can be seen from the results of the rank analysis conducted using the Kruskal-Wallis one-way analysis of variance, the forms of manifestation of aggressive impulses by the type of momentary state of anger, the expression of anger inside and resentment are most pronounced in respondents with a high level of PTSD. Meanwhile, a tendency to irritability and anger is more characteristic of respondents characterized by an average level of severity of PTS, while a tendency to compromise is more characteristic of respondents with a low level of PTS.

Thus, based on the analysis, we can state that the experience of intense stress, manifested primarily in the form of PTSD may be accompanied by the development of certain aggressive reactions and impulses, which may have both personal and reactive nature.

However, an important element in the manifestation of aggressive impulses can be expressed subjective idea of revenge of the individual, which can act as a kind of guide in the implementation of aggressive intentions of the traumatized person. It should be noted that it is not always aggressive reactions may be addressed to the direct object and the "true" target of revenge. In the context of experiencing intense stressful conditions, as clinical practice shows, the objects of violence and aggression by survivors of psychotraumatic situations, very often become close or random people who have no relation to the traumatic experience of the subject of violence. In the framework of this study, we have studied the personal characteristics of aggressive manifestations (with P. A. Kovalev's personal aggressiveness questionnaire) depending on the subjective expression of the respondents ' ideas of revenge. So, as a result of the analysis (using the Kruskal-Wallis one-way analysis of variance), statistically significant differences were revealed in the severity of the two forms of aggressive behavior of the person (suspicion and a tendency to attack the style of behavior and communication), taking into account the presence or absence of the idea of revenge (including its subjective severity). The data obtained are shown in table 2.

Table 2. Rank indicators of the severity of personal aggressiveness of respondents, taking into account the subjective assessment of the severity of the idea of revenge $(\mathrm{N}=100)$

\begin{tabular}{|l|l|c|l|}
\hline $\begin{array}{l}\text { Personality aggression variables } \\
\text { (with P. A. Kovalev's personal } \\
\text { aggressiveness questionnaire) }\end{array}$ & $\begin{array}{l}\text { The severity of the } \\
\text { idea of revenge }\end{array}$ & Assigned rank & $\mathrm{X}^{2} / \mathrm{P}$ \\
\hline \multirow{2}{*}{ Suspicion } & absents & 1 & $\begin{array}{l}\chi^{2}= \\
6,267\end{array}$ \\
\cline { 2 - 5 } & poorly expressed & 2 & 2 \\
\hline
\end{tabular}




\begin{tabular}{|c|c|c|c|}
\hline & strongly expressed & 3 & D- -094 \\
\hline \multirow{3}{*}{$\begin{array}{l}\text { Tendency for the offensive, } \\
\text { attacking style of behavior and } \\
\text { communication }\end{array}$} & absents & 1 & \multirow[t]{3}{*}{$\chi^{2}=5,749$} \\
\hline & poorly expressed & 2 & \\
\hline & strongly expressed & 3 & \\
\hline
\end{tabular}

So, as can be seen from the results of the analysis (see table.2) it is reliably established that respondents with a strong idea of revenge are characterized by a tendency to attack the style of behavior and communication, as well as suspicion. From the results of statistical analysis it is clear that these forms of aggressive behavior tend to grow depending on the subjective level of severity of the idea of revenge.

Thus, the results of empirical research, allow us to argue that persons who have experienced traumatic stress in the past, at a remote stage of a long-term emergency can be characterized by the development of intense stress reactions, manifested primarily in the form of reactions of post-traumatic stress disorder. This, in turn, leads to the development of aggressive impulses, which can be realized by the type of manifestation of momentary reactions of anger, the orientation of anger inward (that is, on the individual experiencing intense stress), irritability, resentment and suspicion. All this against the background of the inability of the individual to compromise can also contribute to the formation of certain ideas of revenge, and the most characteristic aggressive reactions in this case, as shown by the analysis, can be suspicion and a tendency to offensive and attacking style of behavior and communication.

\section{Research Findings}

Intense stress, manifested in the form of post-traumatic stress, at a remote stage of an extreme situation is accompanied by the formation of various aggressive impulses, expressed in the form of such reactions as suspicion, resentment, a tendency to momentary anger and irritation, autoaggressive orientation of the individual, as well as a decrease in the ability of the individual to compromise.

It is established that a high subjective level of expression of the idea of revenge in the context of experiencing intense stress can be accompanied by the development of aggressive impulses of the individual, manifested primarily in the form of suspicion and a tendency to use an attacking and aggressive style of behavior and communication in relation to the social environment.

The work was supported by the grant Council of the President of the Russian Federation for the state support of young Russian scientists - candidates of Sciences (Competition - MK-2018) (MK2469.2018.6 "Ways to implement aggressive motives and ideas of revenge in the context of experiencing high-intensity stress").

\section{References}

1. E.N. Dymova, N.V. Tarabrina, N.E. Kharlamenkova, VMU, 2, 37-50 (2015)

2. E.O. Lazebnaya, Psychological determinants of personal safety of subjects of dangerous types of professional activity, (IP RAS, Moscow, 2012)

3. N.E. Kharlamenkova, SPO, 2, 51-60 (2015)

4. A.G. Karayani, Yu.M. Karayani, Yu.P. Zinchenko, NPJ, 1 (13), 65-73 (2014)

5. A. L. Zhuravleva, E. A. Sergienko, Stress, burnout, coping in a modern context (IP RAS, Moscow, 2011)

6. N.V. Tarabrina. Psychology of post-traumatic stress. (IP RAS, Moscow, 2009)

7. N.V.Tarabrina, I.S. Khazhuev, EP, 3, 215-226 (2015) 
8. N.V. Tarabrina, N.E. Kharlamenkova, M.A. Padun, I.S. Khazhuev, N.N. Kazymova, Yu.V. Bykhovets, M.V. Dan. Intense stress in the context of psychological safety. IP RAS (2017)

9. Y.Hamama-Raz, Z. Solomon, A. Cohen, A. Laufer, JTS, 21(6), 521-529 (2008)

10. Yu.V. Bykhovets, N.V. Tarabrina Psychological Assessment of the Terrorist Threat Experience: A Guide. IP RAS (2010)

11. K.A. Idrisov, HPLC, 7, 21-34 (2011)

12. M.A. Padun, A.V. Kotelnikova. Mental trauma and the picture of the world: Theory, empiricism, practice (Kogito Center, Moscow, 2012)

13. N.V. Tarabrina, I.S. Khazhuev. The Psychology of Everyday and Traumatic Stress: Threats, Consequences, and Possession, 179-192 (2017)

14. I.S. Khazhuev, N.V. Tarabrina, Psychology of everyday and traumatic stress: threats, consequences and coping (2017)

15. M. Jakupcak, D. Conybeare, L. Phelps, S. Hunt, H.A. Holmes, B. Felker, M. Klevens, M.E. McFall, JTS, 6, 945-954 (2007)

16. M.J.J. Kunst, IJ LP, 34(1), 362-367 (2011)

17. S. Lancaster, S. Melka, B. Rodriguez, Psych. Trauma: Theory, Research, and Policy, 3(4), 313-317 (2011)

18. G. Stevens, M. Taylor, M. Barr, L. Jorm, M. Giffin, R. Ferguson, K. Agho, B. Raphael, Austr. and NZ Journ. of Pub. Health, 33(4), 339-346 (2009)

19. T. McHugh, D. Forbes, G. Bates, M. Hopwood, M. Creamer, CPR, 32(1), 93-104. (2012)

20. N.V. Tarabrina. A practical guide to the psychology of post-traumatic stress. At $2 \mathrm{H}$. Part 2. Forms of methods, (Kogito Center, Moscow (2007) 